\title{
Editorial
}

\section{Target Blood Pressure Level in the Management of Hypertension}

\author{
KMHS Sirajul Haque
}

(Bangladesh Heart Journal 2016; 31(2) : 50-51)

Hypertension is a common medical problem encountered in clinical practice in developed, as well as, in developing countries, affecting both urban and rural population. It is one of the leading causes of the cardiovascular complications like myocardial infarction, heart failure and stroke. Moreover, clustering of other risk factors of ischemic heart diseases is associated with hypertension. Almost $1 / 3^{\text {rd }}$ of end-stage renal disease requiring hemodialysis are due to hypertensive renal diseases. Different clinical trials showed that control of hypertension by life style modification and pharmacological interventions reduce the risk of complications like stroke, myocardial infarction and heart failure. In ASCOT-BPLA trial, amlodipine and perindopril provide mortality and morbidity benefit as compared to beta-blockers and diuretics and this trial influenced the modification of many national and international guidelines. Four drugs like angiotensin converting enzyme inhibitor (ACEi), calcium channel blocker (CCB), angiotensin receptor blocker (ARB) and diuretic are brought in the front line and beta blocker has been advocated in case of compelling ground. In ADVANCE trial, combination of perindopril and indapamide showed the benefits of blood pressure reduction along with reduction of both microvascular and macrovascular events in diabetic hypertensive patients.

Clinicians know lot about antihypertensive drugs but face problem at what blood pressure threshold, treatment should be started to reach a target blood pressure level as goal of treatment for the clinical benefit of patients. The problem of relationship of $\mathrm{J}$ point has also barred the doctors for taking therapeutic measures aggressively because the level of blood pressure achieved at certain point of treatment is not beneficial rather increase the cardiovascular events. Finding of Syst-Eur trial differ with the J-shaped phenomena regarding too much lowering the blood pressure.

Address of Correspondence: KMHS Sirajul Haque, Professor of Cardiology, Anwar Khan Modern Medical College, Dhaka, Bangladesh, E-mail: kmhssiraj@gmail.com
Since, 1977, different guidelines have been put forward from different societies and many muntries. Recommendation of JNC-7 regarding definition and classification was widely accepted and practiced for more than one era. In 2014, experts panel members appointed to the Eighth Joint National Committee came out with an evidence based guideline for the nanagement of high blood pressure in adults. Nine recommendations were given based on scientific evidence from randomized controlled trial or their own expert opinion. Patients at 60 years or older should have goal blood pressure less than $150 / 90 \mathrm{mmHg}$ and those aging 30 to 59 years should have blood pressure less than $140 / 90 \mathrm{mmHg}$. The same thresholds and goals are recommended for hypertensive adults of less than 60 years having diabetes or non-diabetic chronic kidney diseases.

SPRINT trial was done in hypertensive patients with high cardiovascular risk, elderly patients ged $>75$ years, CKD patients, patients with preexisting sub clinical or clinical cardiovascular disease, those with Framingham 10 years cardiovascular risk score of $15 \%$ or above, but all were without diabetes. This trial reports considerable reduction of primary outcomes including heart failure by $38 \%$, death from cardiovascular cause by $25 \%$, myocardial infarction by $17 \%$, stroke by $11 \%$, and non-Ml acute coronary syndrome by $0 \%$. In this trial, when target blood pressure had been less than $120 \mathrm{mmHg}$, risk of death from all cause was by $27 \%$. Sprint trial uses automated office BP measurement that correlates more with home BP measurement than with auscultatory office BP measurement. Intensive BP control reduces the risk of heart failure due to more use of diuretics that drives the beneficial effect i.e. primary composite end point. Hypertension should be early detected by office BP measurement compared and confirmed by out-office BP measurement. Office BP measurement is used for high risk patient like elderly patient without orthostatic hypotension, proteinuric chronic kidney disease, eGFR $<60$, patient with cardiovascular diseases risk of 
Framingham score more than 15\%. Beneficial effect of the SPRINT trial could not be comparable with that of ACCORD trial as SPRINT study did not include diabetic patient. SPRINT research group reported serious adverse events like syncope, injurious fall, bradycardia, but hypotension, electrolyte imbalance, and acute kidney injury or acute renal failure were more concerning in intensive treatment group.

In diabetic patient systolic BP target should be $<140$ $\mathrm{mmHg}$ but for patient with or without diabetes plus proteincreatinine ratio more than $500 \mathrm{mg} / \mathrm{gm}$. (albumincreatinine ratio $>300 \mathrm{mg} / \mathrm{gm}$.) lower systolic BP target had been proposed for renal protection targeting $\mathrm{SBP}<130 \mathrm{mmHg}$.

The HOPE-3 trial showed that fixed-dose treatment with low-dose statin therapy, but not BP agents, is superior to placebo in reducing long-term cardiovascular events in an intermediate-risk population; the trial did not support aggressive lowering of blood pressure. Diastolic BP target should not be less than $70 \mathrm{mmHg}$ because it raises the chance of ischemic heart events or risk of acute renal failure in diabetic patient.

Reduction of BP of in hypertensive patients is desirable up to the optimum level but appropriate measures taken by the clinician depend on one's judgment in the perspective of the patient's clinical condition. Results of ongoing and future therapeutic trials will determine the mode of management of hypertension in future.

\section{Further reading:}

1. Jarraya F. Treatment of Hypertension: Which Goal for Which Patient? Adv Exp Med Biol. 2016 Oct 9. [Epub ahead of print].

2. Yusuf S, Lonn E, Pais P, Bosch J, Lopez-Jaramillo P, Zhu J, et ah; HOPE-3 Investigators. BloodPressure and Cholesterol Lowering in Persons without Cardiovascular Disease. N Engl J Med. 2016 May 26;374(21):2032-43. doi: 10.1056/ NEJMoal600177. Epub 2016 Apr 2.

3. Mozaffarian D, Benjamin EJ, Go AS, Arnett DK, Blaha MJ, Cushman M, et al. Heart Disease- and Stroke Statistics-2016 Update: A Report From the American Heart Association. Circulation.2015 Dec 16.pii: CIR.0000000000000350.

4. Sprint Research Group, Wright JT Jr, Williamson JD, Whelton PK, Snyder JK, Sink KM, et al. A randomized trial of intensive versus stndard blood pressure control. N Engkl J Med. 2015 No. 26; 373(22): 2103-16, Koi; 10.1056/NeJMoal1511939. Epub 2015 Nov 9.
5. James PA, Oparil S, Carter BL, Cushman WC, Dennison-Himmelfarb C, Handler J, et al. 2014 evidence-based guideline for the management of high blood pressure in adults: report from the panel members appointed to the Eighth Joint National Committee (JNC 8). AMA. 2014 Feb 5;311(5):50720. doi: 10.1001/jama.2013.284427.

6. WHO/SEARO/Country Office for Bangladesh and DGHS, Ministry of Health and Family Welfare. National Guidelines for Management of Hypertension in Bangladesh. World Health Organization, 2013. Available at: http://searo.who. int/bangladesh/publications/hvpertension in_ban.pdf?ua=l.

7. Mancia G, Fagard R, Narkiewicz K, Redon J, Zanchetti A, Bohm M, et al. 2013 ESH/ESC guidelines for the management of arterial hypertension: the Task Force for the Management of Arterial Hypertension of the European Society of Hypertension (ESH) and of the European Society of Cardiology (ESC). Eur Heart J. 2013 Jul;34(28):2159-219. doi: 10.1093/eurheartj/ehtl51. Epub 2013 Jun 14.

8. Patel A; ADVANCE Collaborative Group, MacMahon S, Chalmers J, Neal B, Woodward M, et al. Effects of a fixed combination of perindopril and indapamide on macrovascular and microvascular outcomes in patients with type 2 diabetes mellitus (the ADVANCE trial): a randomised controlled trial. Lancet. 2007 Sep 8;370(9590):829-40.

9. Dahlof B, Sever PS, Poulter NR, Wedel H, Beevers DG, Caulfield $\mathrm{M}$, et al.; ASCOT Investigators. Prevention of cardiovascular events with an antihypertensive regimen of amlodipine adding perindopril as required versus atenolol adding bendroflumethiazide as required, in the AngloScandinavian Cardiac Outcomes Trial-Blood Pressure Lowering Arm (ASCOT-BPLA): a multicentre randomised controlled trial. Lancet. 2005 Sep 10-16;366(9489):895-906.

10. Chobanian AV, Bakris GL, Black HR, Cushman WC, Green LA, Izzo JL Jr, et al.; National Heart, Lung, and Blood Institute Joint National Committee on Prevention, Detection, Evaluation, and Treatment of High Blood Pressure; National High Blood Pressure Education Program Coordinating Committee. The Seventh Report of the Joint National Committee on Prevention, Detection, Evaluation, and Treatment of High Blood Pressure: the JNC 7 report. JAMA. 2003 May 21;289(19):256072. Epub 2003 May 14. 